\title{
THE SPECIAL OF STRUCTURAL REFORMS IN RUSSIAN SCIENCE
}

\author{
I.Dezhina
}

In Summer-Autumn, the period of structural reforms in Russian science began, that is, establishment of a new Federal Agency of Research Institutions, reforming of the system of three state academies and development of a new Russian Research Fund. The lines of the reforms are not brought in harmony with one another and a number of serious aspects which have a long-term effect on the state of science was not elaborated. Approaches to structural reforms point to a deep crisis in state management of science.

Late in June 2013, the process of reforming of the country's research complex began; the above complex was probably the most substantial one since the beginning of the 1990s when after the collapse of the USSR new institutes in the sphere of science were established. In July-October, several large-scale developments took place: a merger of three state academies - the Russian Academy of Sciences (RAS), the Russian Academy of Medical Sciences (RAMS) and the Russian Academy of Agricultural Sciences $(\text { RAAS })^{1}$ - with simultaneous deprival of their control over research institutes which were subordinate them, establishment of a new Federal Agency of Research Institutions and development of the criteria and mechanism of evaluation of academic institutes. The project to establish the Russian Research Fund was made public. At the same time, the work on appraisal of performance of national research universities (NRU) - the cycle of budget funding of a portion of the above NRU was completed in 2013 - was carried out. The above developments should be analyzed together, though no connection between them is explicit at the first glance.

Draft law No. 305828-6 on The Russian Academy of Sciences, Reorganization of State Academies of Sciences and Amendment of Individual Statutory Acts of the Russian Federation emerged unexpectedly even to the administration of the Academy, so, it was received negatively by a larger part of the research community. Indignation was caused not only by the content of the draft law, but also the method which was selected for carrying out of the reform. In violation of the existing legislation in accordance with which public hearings are to be conducted, the draft law was introduced directly to the State Duma. The profile ministry - the Ministry of Education and Science of the Russian Federation (MES) - declared that it was not the architect of that draft law and the mystery about the authorship

1 RAS - the Russian Academy of Sciences, RAMS - the Russian Academy of Medical Sciences and RAAS - the Russian Academy of Medical Sciences. still prevails which very fact is noteworthy. After two readings of the draft law, the administration of the RAS suggested that five principal amendments should be introduced:

1) Reorganize the RAS by means of a merger with the RAMS and the RAAS, rather than liquidate it.

2) Formulate the main goal of the RAS as carrying out of fundamental and applied research.

3) divide the authorities between the RAS and the Agency (later called the Federal Agency of Research Institutions (FARI)) so that the FARI was entrusted with the single function, that is, management of the RAS property.

4) return the status of a legal entity to RAS regional branches.

5) preserve a two-step system of ranks (a corresponding member and an academician) and reserve with the RAS the right to decide how and when to elect its new members.

The list of amendments explicitly reflects the extent of the government's intensions. It is to be noted that the draft law was negligently prepared and included discrepancies even after two readings in the State Duma.

On the basis of three readings, the RAS succeeded in defending most amendments, including those as regards reorganization by means of a merger of three academies, preservation of the function of the RAS to carry out fundamental and applied research, as well as coordination of research at higher educational establishments (HEE), reestablishment of regional branches as independent legal entities and preservation with the Academy of the status of the main administrator of budget funds on research, including maintenance of activities of regional branches. Finally, the rank of a corresponding member of the RAS was preserved. However, the RAS was deprived of its authorities to act as the owner of federal property which was vested in research institutions under its jurisdiction. As a result, the situation of research institutions has become the most uncertain one. 
The law was approved on September $27^{1}$ and on the same day the Decree of the President of the Russian Federation on the Federal Agency of Research Institutions $^{2}$ was issued. Only after the Decree had been issued the work on development of guidelines for activities of the FARI and its authorities began. Actually, a new ministry of science emerged and it was assigned research institutions which were under jurisdiction of state academies. As the above developments will inevitably result in changes in the existing portion of the research complex which has been the most efficient one up till now (as regards the number of publications and their quoting), the Commission on Non-Government Supervision over the Reform of the Academy of Sciences was established (on October 8). The situation prompted consolidation of the civil society movement in science: ten non governmental entities of science and education joined the above Commission ${ }^{3}$. Such a consolidation can be regarded as a positive indirect effect of the poorly devised reform of the academic sector of science.

The Commission which existed only for a week focused on introduction of amendments into the statutes on the FARI as in the document which was developed in the government the role of the Agency was changed from a soft regulator to a tough centralized manager. In particular, in the first version the function of a coordinator of activities of research institutions, expertise and scientific methods was reserved with the RAS, but later it was deprived of that function ${ }^{4}$.

Debates on the draft law were to last till October 26, however, on October 16 the draft law was submitted to the government ${ }^{5}$. The fate of amendments which were still in the process of development remained unclear.

The draft statutes of October 18 on the FARI - the latest version available for the public analysis - suggests that all the key issues related to financing, property of the research institutions, the social sphere and purchase of the equipment and chemical agents are the prerogative of the Agency. In the text, the RAS was

1 №253, 27.09.2013 http://graph.document.kremlin.ru/page. aspx?1;3586986

2 №735 27.09.2013 http://graph.document.kremlin.ru/page. aspx?1;3587023

3 Scientist established a Commission on Non-Government Supervision over the Reform of the Academy of Sciences. http:// www.polit.ru/news/2013/10/08/public_control_in_science/ October 8, 2013.

4 S.Samokhina, N.Gorodetskaya, A.Chernykh and Kh. Aminov. The Complex Situation // Kommersant No.184, October 9, 2013 http://www.kommersant.ru/doc/2315297

5 P.Kotlyar. Nothing Will be Left Either to the Academy or Scientists. The Statutes on the New Agency will be Submitted to the Government without Debates. http://www.gazeta.ru/ science/2013/10/15_a_5709173.shtml 15.10.2013. referred to only twice. The first mention of the RAS was as follows: The proposals of the RAS are expected to be taken into account only in approving by research institutions of state assignments on fulfillment of fundamental and applied research. The second mention of the RAS: The RAS participates in formation of the scientific and coordination council by nominating candidatures of their representatives. It is to be noted that the role of the Council is not that great. A limited range of issues is expected to handled with approval of the council; such issues include assessment of research institutions, as well as a proposal on establishment, reorganization and liquidation of research institutions which are under the jurisdiction of the FARI.

The work on development of the draft statutes on evaluation of efficiency of research institutions was less in the highlight ${ }^{6}$, though, logically, such an evaluation should be the basis of audit of academic institutions which are assigned to the jurisdiction of the FARI.

As seen from the text of the draft law, evaluation will be of an extradepartmental nature and it is carried out on the basis of comparison of reference groups of institutes.

The extradepartmental nature of evaluation is expected to be ensured by means of establishment of the Interdepartmental Commission on Evaluation of Efficiency of Research Institutions. The above Commission is entrusted with handling quite a lot of issues, including determination of the minimum values of the indices which situation is very important and predetermines to a great extent the outputs of evaluation. However, in the text the guidelines for formation of such a commission and personnel selection criteria are not specified.

Another aspect is reference groups and general evaluation principles. The latter can be understood only after reading an explanatory note to the draft law - according to the above explanatory note the expert community may be engaged in that work, but proceeding from the context there will be exceptionally quantitative evaluation on the basis of a set of 25-30 indices. In this connection, it remains unclear if the qualitative and quantitative evaluations correlate? If the qualitative evaluation is envisaged, it remains unclear which one: at the stage of making up of reference groups or somewhere else? It is to be noted that formation of reference groups requires a thorough expert approach as it is rather complicated to compare the areas of expertise with taking into account the specifics of the work and, in case of need, "sources and mecha-

6 The draft resolution of the Government of the Russian Federation on Amendment of Resolution No. 312 of April 8, 2009 on Evaluation of the Efficiency of Activities of Research Institutions Engaged in R\&D. 
nisms of funding, as well as the form of incorporation of research institutions. So, the criteria of selection of experts need to be specified, as well, there is no mention of the word "expert" and its derivatives in the text of the draft resolution.

It is unclear how the evaluation of the RAS institutes will be related - if related - with the government's intensions to develop academic research, including by way of support of NRUs and allocation of substantial funding to 15 higher educational establishments of which at least five universities are to be included in the world's 100 top universities by 2020 . For a NRU, a closer cooperation up to a take-over of academic research groups could be advantageous. Assessment of the performance of NRU in 2013 showed that they lag behind as regards scientific and technological activities: publication activities and, particularly, quoting and patenting ${ }^{1}$.

Finally, another related line of reforms is the project of establishment of the Russian Research Fund which may dramatically change the composition of institutes of support of academic research. Draft Law No.308179-6 on the Russian Research Fund was approved in the second reading on September 18, 2013. The need of expansion of grant financing of science was discussed for quite a long time as well as the need to have a variety of funds. However, judging by the position of the new fund among other institutes and instruments it seems it will sooner be a substitution of the existing organizations, rather than a complementary one.

The range of the Fund's authority is defined rather broadly: it will deal with all those issues which are currently handled by research funds (the Russian Fund of Fundamental Studies and the Russian Humanitarian Research Fund): also a number of projects funded within the frameworks of federal purpose programs (for example, measures aimed at support of research

1 T.Kondrakova. With Other Non-Equal. NRU were Estimated Without Discount as Regards the Difference in Potentials // Poisk, No.41, October 11, 2013, p.6. and educational centers, groups led by representatives of diasporas and mega-grants) may be assigned to the Fund. The Fund will allocate grants in the amount of $\mathrm{Rb}$ $5 \mathrm{~m}-\mathrm{Rb} 29 \mathrm{~m}$ on research on the competitive basis to support projects for the term of 3-7 years. The range of the types of the projects is a broad one: from development of the mega-science policy to strengthening of the personnel potential of research and educational institutions. It is unclear whether the authorities between the existing entities and the new fund are going to be divided or a partial overlap is envisaged.

In addition to the above, the Fund may engage in entrepreneurial activities and found economic entities, that is, to be a surprising hybrid of anything possible; the above specifics is not normally utilized in other funds which are not incorporated as a "fund", though such a possibility for research funds has been discussed since 2001. Probably, emergence of a new fund is related among other things to reforming of the academic sector, but the principles of networking between the RAS, the Federal Agency of Research Institutions, the MON and the Fund are not specified.

In the mid-term prospect, the possible consequences of the reform of the academic sector of science can be assessed as negative. Reduction of the number of institutes will be accompanied by a partial loss of the personnel (due to, among other things, an outflow to abroad). Consequently, efficiency of research in the country will decrease at least for some time (years). If the property is administered without taking into account the specifics and the value of the research, damage may be caused to collections, museums and archives.

The decision-making methods in restructuring of the research complex, lack of harmony between measures which are developed concurrently and have an effect on science and the low level of development of the above measures point to a deep crisis of state regulation of science. 